\title{
IMAGENS TÉCNICAS E IMAGENS MENTAIS: CONTRIBUIÇÕES DO PENSAMENTO FILOSÓFICO DE C. TÜRCKE PARA UMA LEITURA DE “TERRA EM TRANSE” NA FORMAÇÃO DE PROFESSORES.
}

\author{
TECHNICAL IMAGES AND MENTAL IMAGERY: CONTRIBUTIONS \\ OF C. TÜRCKE'S PHILOSOPHICAL THOUGHT TO A READING OF \\ "EARTH IN TRANCE" IN TEACHER TRAINING.
}

\author{
Luciana Azevedo Rodrigues ${ }^{1}$ \\ Márcio Norberto Farias ${ }^{2}$
}

Recebido em: 02/2018

Aprovado em: 03/2018

\begin{abstract}
Resumo: O filme " Terra em transe" é analisado neste trabalho a partir do pensamento de C. Türcke sobre o processo histórico e social de sedimentação e dessedimentação do sensório humano. Nele, são retomados os conceitos de compulsão a repetição traumática, exploração da concentração, dessedimentação e ressedimentação da capacidade de concentração. No desenvolvimento da análise, destaca-se um modo peculiar de evidenciar a precariedade na produção das imagens em relação viva com a precária condição do corpo humano frente ao aparato técnico de produção das imagens. A análise da estética do filme fundamentada nos conceitos filosóficos estudados evidencia-o como alegoria da necessidade humana de recuperação dos abalos sofridos seja com o Golpe Militar de 1964 seja com o turbilhão de imagens audiovisuais dos tempos atuais. Os nexos elaborados entre o transe do filme e o do tempo atual tem em vista provocar a reflexão de professores/professoras em torno da necessidade de valorizar o exercício de formar imagens mentais e o olhar retrospectivo do "transe" diário que vivem em suas práticas pedagógicas como caminho na direção de reduzir os efeitos deletérios de tal transe para o domínio da própria atenção.
\end{abstract}

Palavras-chave: filme- compulsão a repetição- transe- concentração

\begin{abstract}
The film "Earth in trance" is analyzed in the work from the thought of C. Türcke on the historical and social process of sedimentation and desedimentation of the human sensorium. In it, the concepts of compulsion to traumatic repetition, exploration of concentration, desedimentation and resurgence of the ability to concentrate are resumed. In the development of the analysis highlights a peculiar way of evidencing a precariousness in the production of images in living relation with a precarious condition of the human body in front of the technical apparatus of production of the images. Analysis of the aesthetics of the film based on the studied philosophical concepts evidences it as allegory of the human need to recover the shocks suffered with the
\end{abstract}

\footnotetext{
${ }^{1}$ Luciana Azevedo Rodrigues. Professora do Departamento de Educação da Universidade Federal de Lavras. Doutora em Educação com pós doutoramento em Filosofia junto a Universität Leipzig. Coordenadora do Projeto "O cinema como experiência inovadora da formação cultural de professores", apoiado pela FAPEMIG.

${ }^{2}$ Marcio Norberto Farias. Professor do Departamento de Educação Física da Universidade Federal de Lavras. Doutor em Sociologia com pós-doutoramento em Filosofia junto a Universität Leipzig. Vice-coordenador do Projeto "O cinema como experiência inovadora da formação cultural de professores", apoiado pela FAPEMIG
} 
Military Coup of 1964 or with the whirlwind of audiovisual images of the present times. The nexus elaborated between the trance of the film and the current time in the view provoke a reflection of teachers / teachers around the need to value the exercise of mental imaging and the retrospective look of the daily "trance" that live in their pedagogical practices as a way in the reduce the deleterious effects of such a trance to the domain of own attention.

Keywords: film-compulsion a repetition-trance-concentration

\section{Introdução}

O pensamento do filósofo C. Türcke (2010a, 2010b, 2017) sobre o processo histórico e social de sedimentação e dessedimentação do sensório humano, não discute especificamente o cinema e suas diferentes vertentes, mas oferece os pressupostos filosóficos, históricos e sociais para elaboração das reflexões desenvolvidas ao longo deste trabalho sobre o tema. Nele, a proposta é analisar a estética do filme " Terra em transe" de Glauber Rocha tendo em vista a construção de um trabalho com o cinema na formação de professores comprometido com o fortalecimento da capacidade das pessoas de se auto concentrarem.

Este filme que completa 50 anos em 2017, em meio a convulsões políticas no Brasil, não é analisado aqui como uma profecia do cenário político partidário brasileiro, ou como uma ilustração dos acontecimentos recentes do golpe no Brasil de 2017, mas é observado como uma estética que, apoiada na alegoria e na saturação de sons e imagens construiu uma experiência diegética do transe, que alegoriza não apenas "o trópico enquanto palco da empresa colonial e de seus prolongamentos", tal como explica Xavier, 2007, p. 194) mas também a atenção humana como um novo espaço de exploração em meio a configuração atual do modo de produção capitalista, que, tal como diz Türcke, intensificou o processo de exploração do sistema nervoso humano.

Por isso, o trabalho se volta para o filme, dialoga com a análise de Ismail Xavier sobre ele e se fundamenta no pensamento de C. Türcke, presentes nos livros Sociedade Excitada(2010), Filosofia do Sonho (2010) e Hiperativos (2017), se pautando especialmente nos conceitos de compulsão a repetição traumática, exploração da concentração, dessedimentação e ressedimentação da capacidade de concentração. Estes conceitos formam as condições para a elaboração de alguns nexos entre a experiência de transe representada alegoricamente no filme e a experimentada pelas pessoas em meio a avalanche de choques audiovisuais na cultura contemporânea. A elaboração de tais nexos tem em vista provocar a reflexão de professores/professoras em torno do "transe diário" que vivem em suas práticas 
pedagógicas na relação com o cinema e com os materiais audiovisuais em geral.

\section{Dessedimentação e ressedimentação entre duas formas do repetir}

C. Türcke (2010a, 2010b), na tradição da crítica imanente, própria a Teoria Crítica da Sociedade, faz emergir novos sentidos do pensamento de Marx, Freud, Adorno e Benjamin para mostrar que é na sociedade de mercado capitalista, na desestabilização profunda das condições sociais para a formação do indivíduo, que também emergem e proliferam as imagens audiovisuais, técnicas, não mentais que encantam cada vez mais as pessoas por seu brilho, nitidez e sobretudo, por parecerem reais.

É no centro deste processo que o filósofo se refere a uma exploração do trabalhador que não se limita a mais valia não paga, tal como apontada por Marx, a qual se realiza como desgaste progressivo do sistema nervoso das pessoas. Sua reflexão, parte da análise marxiana sobre a subsunção formal e real do trabalho ao Capital e aponta que da época de Marx até o presente momento, a subsunção real do trabalho se desdobrou em subsunção real do tempo livre com a subordinação do aparato perceptivo, primeiro ao cinema, com suas imagens em movimento e; posteriormente, à tela do computador tornada ferramenta central e individual do processo produtivo, diante da qual o sensório humano permanece durante longo tempo.

Türcke (2010a) não só retoma a teoria marxiana para evidenciar a exploração da concentração em paralelo com a da mais valia, mas recupera a caracterização de Marx e Engels (1948) de que a condição moderna é movimento constante que não admite relações duráveis. É atribuindo a esta caracterização uma importância central, que ele aponta para existência de uma privação sentida por homens e mulheres na modernidade - a privação de relações duradouras. Türcke (2010a) passa então a refleti-la por meio da teoria pulsional freudiana, especialmente dos seus conceitos de fetiche e compulsão a repetição traumática.

Os conceitos freudianos, entretanto, são retirados do universo terapêutico e estendidos para uma reflexão em torno da formação histórica e social da cultura. Com isso, Türcke (2010a, 2010b) constrói um arcabouço teórico que compreende a repetição como um processo realizado pelo frágil organismo humano ao longo de sua história para restrospectivamente reviver/representar os acontecimentos que o atingiram de forma traumática e assim, conseguir em práticas sociais reduzir os seus efeitos traumáticos - um processo de repetição que deixou 
seus vestígios históricos nos ritos sacrificiais- a partir do qual a cultura e o próprio sensório humano foram sendo sedimentados.

Também se utilizando da teoria do fetiche freudiano para além do universo terapêutico, Türcke (2010a) discorre sobre a relação viciante das pessoas com as imagens audiovisuais como uma espécie de experiência substitutiva que obsta à consciência a privação decorrente da progressiva eliminação de espaços e tempos sociais historicamente forjados e que propiciaram a experiência de viver com, de construir vínculos e de sedimentar relacionamentos - eliminação que se intensifica com o avanço da lógica de mercado capitalista.

Noutras palavras, Türcke (2010a) não apenas discorre sobre o movimento histórico do desenvolvimento tecnológico sobre o qual se desdobrou a subsunção real do trabalho em subsunção real do tempo livre com sua retroversão para o tempo de trabalho, mas também aponta para um processo histórico subjetivo de privação decorrente do desenraizamento das pessoas imposto com o surgimento e avanço do mercado capitalista.

É neste contexto, que o filósofo aponta que os sujeitos em condições de desenraizamento constante lançam mão de mecanismos que prometem substituir tal privação, sendo um deles o consumo das imagens em movimento.

Um consumo que também é marcado por uma dimensão permanente de repetição, que, entretanto, não dispõe do caráter terapêutico da compulsão a repetição descoberta por Freud e ampliada por Türcke para compreender o processo de formação da cultura. Isto porque em vez de uma efetiva relação do organismo humano com as coisas, assim como com o exercício de associação e representação do trauma/privação social, o que se observa é um mecanismo substituto, que por suas próprias características não pode oferecer aos indivíduos apoio algum. Dito de outro modo, tal mecanismo substituto é caracterizado por interromper permanentemente relacionamentos duradouros.

Ao transpor esta discussão para as imagens em movimento- Türcke (2010a, 2010b, 2017) se apoia em Walter Benjamin, especialmente em sua conceituação de que o cinema constitui-se da mudança constante de planos e cenários que interrompem o exercício associativo do pensamento. A partir dela, entretanto, Türcke lembra que ainda na época de Benjamin, nos primeiros anos do cinema, o espectador ainda não estava inundado pela constância da mudança das imagens em movimento e que por isso, conseguia digerir paulatinamente os filmes assistidos, contando-os, relacionando-os com outros momentos de sua vida, nos termos do próprio Türcke "manquejando" atrás das imagens técnicas, ou ainda 
repetindo-as organicamente, uma vez que dispunham de espaços de associação posteriores a exibição do filme, e podiam fazer aquilo que W. Benjamin em seu Imagens de Pensamento Denkbilder (2013) compreendia como dar corpo as ideias. Tal forma de se relacionar com as imagens em movimento, conforme C. Türcke, foi fortemente abalada com a presença constante das telas no cotidiano das pessoas.

A ligação que Türcke (2010b) estabelece entre a caracterização das imagens em movimento de Walter Benjamin com a experiência de seu próprio tempo, quando as pessoas direcionam sua atenção cada vez mais a elas, o faz apontar que as imagens em movimento, como mudança incessante de planos e cenários não remetem para a necessidade de sua interrupção mas carregam em sua própria constituição as marcas daquilo que mantem o sofrimento na sociedade moderna, o impacto do permanente desenraizamento.

Nesses termos, uma primeira leitura de seu pensamento poderia incorrer na afirmação de que se trata aqui de uma filosofia que condena um trabalho pedagógico com as imagens em movimento. Uma segunda leitura, porém, permite compreender a relevância de sua crítica a um olhar que se idealiza capaz de acompanhar o fluxo ininterrupto das imagens em movimento, uma crítica que permite compreender que tal olhar não só obsta à vista a erosão social mas também a erosão da própria capacidade perceptiva dos seres humanos.

Tendo em vista ressaltar essa importância para os estudos do cinema na formação docente, este trabalho aponta para a necessidade de não ficar numa primeira leitura do textos do referido filósofo, assim como para não assistir a filmes como "Terra em transe" apenas uma vez.

Como produções que requerem o mais de uma vez, tanto o pensamento de C. Türcke quanto o filme de Glauber Rocha já se colocam como materiais que precisam da escola e dos/das professores/as para poderem contribuir para a formação humana das próximas gerações. Pois, se num primeiro momento tal filme tende a ser imediatamente considerado um filme de baixa qualidade ou então pode ser interpretado como um exemplo de imagens em movimento que conduzem à interrupção associativa do pensamento, uma segunda leitura permite ver a sua saturação de mudança de cenas e planos, assim como seus momentos de precariedade como promotores do exercício da reflexão crítica.

Seus aspectos formais são considerados neste trabalho como constituintes de um palco que não só possibilita visualizar efeitos traumáticos de choques passados, mas reconhecer a insuportabilidade dos choques do próprio presente, vividos imperceptivelmente no cotidiano das sociedades high tech, quando seguem ininterruptamente o fluxo das imagens em 
movimento no esforço de si identificarem com a eficiência da máquina. Um processo que as tornam ainda mais presas de uma forma atual de transe.

Nesses termos, o filme é destacado não apenas como uma manifestação estética da mudança permanente das condições e das relações sociais dos indivíduos que interrompem a construção de apoios a partir dos quais poderiam se afirmar diante das pressões frente ao Universal, mas também como uma experiência fílmica que explicita as condições do sensório humano de não acompanhar efetivamente o ritmo das mudanças de cena e planos na vida e na tela, e alegoricamente discute a permanência do transe a partir de processos subjetivos/objetivos que, por não serem reconhecidos em sua força traumatizadora também não conseguem ser elaborados.

Ao radicalizar o choque audiovisual, o filme pode contribuir na percepção do choque vivido diariamente, e dos efeitos de exploração da percepção humana, discutida por C. Türcke como desdobramento de um processo social e histórico marcado pela violência da decomposição. Um processo que atinge tanto as relações sociais que, no passado pré-moderno bem ou mal transmitiam experiências de pertencimento aos seus particulares, quanto o exercício associativo do pensamento, aprendido pelos indivíduos junto as mais diversas atividades materiais e artesanais.

C. Türcke (2010a, 2010b) é enfático ao distinguir a repetição técnica da repetição " orgânica" de imagens, descartando argumentos de que o filme poderia em sua repetição maquinal contribuir para a ressedimentação da percepção. Isso ele não diz, assim como este trabalho não quer dizer, porque tal ressedimentação, assim como ocorreu com a sedimentação, implica no trabalho do próprio organismo humano, no retomar e no se demorar dolorosamente sobre aquilo mesmo que foi sentido pela primeira vez como algo aterrorizante, um retomar que possibilitou às imagens formadas mentalmente se desenvolverem, primeiro, como alucinações e, posteriormente, como representações pálidas e difusas.

Türcke (2010a) reconhece assim que não se trata de uma negação abstrata das imagens em movimento, ou seja da não utilização delas no processo educativo. Para ele, tais imagens exercem um papel fundamental na economia pulsional dos indivíduos submetidos às condições modernas. Ele propõe então dosá-las, de modo que seja valorizado o manquejar atrás delas, o exercício de recuperá-las mentalmente, representá-las e junto desta representação lidar também com aquilo que traumatiza e que sequer é admitido como existente pelos indivíduos pressionados pela lógica de mercado. 
Sua proposição de dosagem e seu reconhecimento de que as imagens em movimento tem um papel central na economia pulsional dos indivíduos, se reflete no destaque que dá a professores e pais que agem na direção da dosagem. Esse destaque chega ao ponto de colocar as ações destas pessoas na mesma tradição crítica da arte de vanguarda do século XX que buscou desenvolver uma estética em que os sentidos não fossem simplesmente reduzidos à meros mecanismos que reagem aos estímulos do meio ambiente.

A teoria de C. Türcke (2010a, 2010b) não apenas discorre sobre a erosão da atenção com o progressivo espraiamento e intensificação da mudança própria do filme no cotidiano das pessoas mas, sobretudo, oferece pressupostos para entender que a atração pelas imagens em movimento está ligada a uma experiência impalpável de privação produzida e reproduzida no interior da sociedade capitalista e como tal não pode ser abstratamente negada. É então com a perspectiva de que as imagens em movimento precisam ser negadas determinadamente, que este trabalho busca dentro das próprias imagens em movimento elementos que possam contribuir para sua dosagem e para o consequente processo de ressedimentação da percepção humana.

Pelas ideias acima expostas, mesmo que o pensamento de C. Tücke não tenha se detido sobre o cinema na formação docente, ele oferece condições para que isso seja paulatinamente construído. Com o intuito de contribuir com algo nesta direção o próximo tópico do trabalho se detém sobre o filme brasileiro " Terra em transe, e com base nas reflexões acima destacadas, busca evidenciar sua verve política num sentido renovado, destacando o como uma alegoria do transe, não apenas o produzido pelo golpe militar mas também pelo silencioso e não menos violento golpe do ininterrupto fluxo de imagens audiovisuais que esgotam a atenção humana.

\section{Da incontornável necessidade de recuperação do que horroriza como ideia chave para pensar Terra em Transe na contemporaneidade.}

Terra em Transe, de 1967, é o terceiro longa metragem de G. Rocha. Em torno dele, muitos estudos foram realizados, no Brasil e em outros países. Foi criticado e elogiado por pessoas identificadas à políticas de esquerda e de direita, mencionado inúmeras vezes como sendo uma crítica no calor das horas ao golpe militar de 64, uma crítica que atacava tanto às forças ultraconservadoras quanto às populistas no quadro político brasileiro. Além 
disso, ele também foi identificado como expressão de uma auto-reflexão crítica do próprio Glauber Rocha como intelectual, artista engajado e afetado com movimentos políticos de sua época.

O desenvolvimento deste trabalho, considera fundamentalmente a análise feita por I. Xavier acerca do filme e parte da ideia de que ele resultou da necessidade irrevogável do poeta de recuperar as forças que o abalaram subjetivamente com o Golpe de 64, algo que ele parece querer expressar ao dizer que com este filme "queria abrir o tema do transe, ou seja da instabilidade das consciências." (apud Viana 2011, p. 168).

Portanto, a ideia chave para a leitura do filme neste trabalho é a da compulsão a repetição traumática, ampliada por C. Türcke para pensar o processo de desenvolvimento da cultura. Com ela evidencia-se que o referido esforço de recuperação das próprias forças abaladas subjetivamente também foi o que conduziu ao seu caráter alegórico e a sua força expressiva também para pensar os choques e o transe em nosso próprio tempo histórico.

Dentro desta perspectiva, a análise retoma aspectos formais do filme que conduzem a reconstituição da experiência do transe, são eles: o corte abrupto e frequente, a montagem vertical, o registro tremido de câmara, a não interrupção de som no exato momento de mudança de cenário, a sobreposição rápida de imagens e de sons que impede de ouvir e ver. Tais aspectos são pensados em conjunto com a centralidade exercida pelo flashback e por outras formas de repetição dentro do filme. E dentro desta estrutura saturada e repetitiva também busca-se evidenciar um momento de precariedade que caracteriza a produção das suas imagens.

\section{Sequência de abertura}

O filme começa com o plano alto e lento da câmera acompanhada pelo ritmo hipnotizante dos tambores e pelo canto de mulheres que repetem a mesma melodia. Ela parte do Atlântico, passa o mar até chegar as costas do país cujo nome passa a ocupar toda a tela sobre um fundo preto: Eldorado, país interior, Atlantico, lugar de desdobramento de toda a trama fílmica, cujo nome é o mesmo das forças das aguas de onde a câmera e o filme inicia seu curso A câmera e a legenda portanto, já anunciam algo mais que o mar e a terra, algo que remete ao interior, à desestabilização subjetiva e que junto aos outros elementos da natureza/naturalizados formam a ambiguidade abordada no filme que conforme I. Xavier 
(1993) se pautou na experiência de G. Rocha com o estilo chamado por Pasolini de Subjetiva indireta livre.

O letreiro em caixa alta antecede o corte que leva para outro cenário, na mudança porém, o canto e os tambores não são simultaneamente cortados, um retardamento técnico que não acompanha a mudança das imagens acaba por evidenciar uma continuidade do canto com batidas muito aproximadas aquelas ouvidas nas paradas militares. Nesta mudança de cenários, a câmera trêmula, desequilibrada e de mudanças rápidas de planos apresenta a curta parte deste filme que não compreende as cenas de rememoração que o "completa". Uma sequência que volta no término do filme ainda mais saturada, modificada pela montagem vertical, pela descorporificação da voz do protagonista, pela sobreposição de sons.

Esta sequência de abertura do filme evoca o golpe de 64 no Brasil trazendo uma encenação em que as forças armadas exigem a renúncia da candidatura do líder populista (Vieira) à presidência, quando o líder imediatamente se entrega e o poeta e jornalista Paulo Martins além de se opor a tal renúncia exorta a luta armada.

Nela, a câmera se evidencia tanto nos registros angulares, tremidos, nos movimentos bruscos, circulares que distanciam e aproximam o espectador testemunhando sua presença como filtro dos acontecimentos, como promotora de desnorteamento, enquanto Paulo, o poeta, a la Brecht e seu teatro didático, exorta o espectador a lidar com a fraqueza daqueles que elegem como líderes.

A sequência termina com o grito indignado do poeta contra a fraqueza do líder popular, e com a abertura de plano da câmera que captura a grandeza do Palácio onde a cena ocorre. A sequência seguinte traz Paulo e Sara, secretária do líder popular dentro de um carro. Nele, Paulo aos gritos discute a fraqueza para enfrentar a luta armada enquanto Sara, em resposta ressalta que é preciso evitar o derramamento de sangue, e evocando Brecht diz não haver necessidade de heróis. Completamente tomado pela ideia da luta armada, Paulo se depara com uma blitz policial, e por não parar o carro acaba ferido enquanto continua proclamando sua necessidade de cantar e de defender valores absolutos.

O corte acontece de modo que se pode ver Paulo em dunas onde tudo que aparece entorno é branco. Ferido de morte e com uma metralhadora em punho aponta-a para o céu, enquanto um poema de Mauro Faustino que enaltece a pureza do sangue do poeta e o seu sacrifício se sobrepõe à tela, a qual por sua vez não dispõe de tamanho suficiente para ele.

É diante da morte, ao se perguntar sobre o que os outros vão dizer de suas loucuras, ao som das Bachianas 3 de Villa-Lobos, e em meio a um branco desnorteador que Paulo profere 
as seguintes palavras "Onde estava a dois, três, quatro anos...Onde? Com Dom Porfirio Diaz navegando nas manhãs com meu Deus da Juventude Dom Porfírio Diaz..." Tal cenário não apenas acentua a importância do rever os acontecimentos que conduziram ao momento traumático mas prenuncia o longo flaschback. É ele que constitui a maior parte de tempo do filme até a volta da cena inicial ainda mais carregada de elementos, que apenas o ver mais de uma vez permite perceber.

\section{A evidencia do aparato e a subjetiva indireta livre.}

A câmera de Terra em transe se evidencia ao espectador, que educado a não considerar a mediação do aparato tecnológico e a ignorar o exercício da montagem tende a desqualificar as imagens tremulas e desfocadas em vez de tomá-las como senhas para a percepção de elementos importantes da obra.

Sobre este modo de utilizar a câmera, I. Xavier esclarece que para Pasolini, uma das característica do cinema moderno é exatamente a evidência do aparato, algo que permite abordar as mediações entre subjetividade e objetividade de uma forma diferente do cinema clássico.

Tal distinção é relevante para reflexão deste trabalho, uma vez que aprender a ver a presença da câmera não é algo que reduz o olhar ou a realidade olhada mas pelo contrário é um modo de ampliar o olhar para fora do quadro fílmico, de tornar a câmera um índice que leva o espectador a se atentar para o aspecto construtivo da obra, para a partir dele construir também uma relação não fetichizada com ela e consigo mesmo, podendo vivenciá-la não como uma ilusão na qual pode mais uma vez se esquecer mas como um produto social do trabalho humano que pode contribuir para o fortalecimento de sua própria percepção e capacidade de representação.

É com a câmera então que o espectador/a experimenta neste filme os primeiros segundos do clima de desorientação abordado no filme. Antes de se expor na fala do narrador e protagonista, tal clima está presente no movimento das coisas. A instabilidade com que a câmera a captura torna-a um meio de expressão. Não só apresenta uma realidade descompassada, mas a própria câmera é usada em descompasso, com o som, com a música e consigo mesma, a medida que traz o registro duas vezes da mesma cena.

Antes mesmo de Paulo Martins entrar em cena o seu estado dilacerado e abalado já se 
fazem sentir no modo como as imagens são feitas. Como esclarece Xavier, em seu livro " Alegorias do subdesenvolvimento"

Paulo ainda não entrou em cena, não tomou a si a responsabilidade pelo relato e já as imagens e sons mostram um estilo que imita sua atitude. A mediação em Terra em transe transcende a subjetividade de Paulo mas assume os padrões da sua experiência. (1993, p. 39, grifo nosso)

Este contágio entre a visão do narrador com a do autor, ou algo externo ao narrador é o que caracteriza, conforme I. Xavier a subjetiva indireta livre.

Para o crítico cinematográfico brasileiro, o filme Terra em transe é um típico exemplo de subjetiva indireta livre, discutido por Pasolini a partir do comentário que fez ao filme Antes da Revolução de Bertolucci. Depois de apontar que ela é para Pasolini a contaminação entre a visão do autor e a do narrador neurótico, Xavier a toma como categoria descritiva ressalvando seu entendimento de que não se trata exatamente da mescla entre a visão do narrador e a do autor mas de algo relacionado a este que contagia a visão do narrador. Nas palavras do próprio crítico brasileiro de cinema

Seja explicito ou não a mediação da subjetividade do poeta em determinada cena, o fato é que seu estilo prevalece, pois é o seu estado de espírito que contamina toda a narração, embora não seja totalmente seu o relato (Xavier 1993, p. 39)

Com este apontamento Xavier possibilita compreender que a câmera e a montagem desequilibradas em Terra em transe se referem tanto aos acontecimentos objetivos da época em que o filme foi feito, de épocas anteriores quanto estão contaminadas pelos efeitos sentidos pela subjetividade, e os conflitos daí decorrentes.

Conforme o crítico, tal técnica possibilita ao espectador uma visão mais compreensiva, interna, da experiência da personagem e o obriga a um constante cotejo entre a imagem que lhe é dada e a noção que ele tem do mundo, já que "o filme não afirma uma realidade estável que o emoldure e explique os movimentos do personagem." (Xavier, 1993,p.39)

Em sua análise sobre os excessos do filme, no livro Sertão Mar, Xavier diz

A mesma sobreposição de lógicas em princípio incompatíveis vai ocorrer em meio a uma avalanche de gestos e de falas, o ritmo deixando o espectador sem fôlego, trazendo a muitos a impressão de caos, pois o filme não 
ressalta os esquemas que, dentro dele, organizam a representação, prevalece a sucessão de choques. E o desconforto se acentua porque o característico embaralhamento de focos- a constituição de um discurso de centro instável, onde a própria enunciação traz a marca de um dilaceramento- tem como elemento catalisador a figura do intelectual-poetajornalista Paulo Martins. (...) A modulação do ponto de vista vai permitir que, na aparência de uma recapitulação a partir da agonia do poeta, se desenvolva de forma ordenada o esquema do mundo e, simultaneamente, se dê conta do jogo de paixões, ressentimentos, delírios e obsessões da consciência agonizante, pondo em questão os pressupostos estéticos e políticos de toda uma época. (2007, p. 195, grifo nosso)

A experiência com a subjetiva indireta livre realizada em Terra em Transe tal como aponta Xavier (1993) junto a agonia do poeta, evidencia a neurose do indivíduo-protagonista que ora adere a norma social do mais forte, ora repele-a compulsivamente quando identifica-a como parte do comportamento de outros. Nesses termos ao apontar os efeitos produzidos pela incapacidade de Paulo em admitir momentos desta adesão em sua própria ação, o filme mostra a condenação do indivíduo a forças míticas, a sua permanência como mera presa em estado permanente de transe. É este enredamento mítico que leva este trabalho a sublinhar que tal condição se prolonga aos dias atuais por meio de distintos mecanismos.

A câmera que repete a atitude compulsiva do protagonista testemunha a ambiguidade conservada em toda obra Terra em transe. A desproporção do volume e fluxo de imagens e sons e a expectativa do espectador de conseguir acompanhar o fluxo permanente das imagens em movimento, o que aqui é tratado como seus esforços de identificação a eficiência da máquina confronta-se com sua dignidade de não ser uma máquina.

Tal desproporção tem como um dos seus efeitos aquilo que neste trabalho consideramos ser uma espécie de negação determinada do movimento das imagens audiovisuais. Dito de outro modo, é por meio de suas sequencias saturadas que o filme leva o espectador a pedir pelo seu cessar; é por meio das próprias imagens que trabalha no sentido de provocar a necessidade da interrupção, a negar a manutenção de seu fluxo e com ele a auto cobrança de continuar submetido.

\section{Montagem vertical e o quadro alegórico}

Xavier (1993), em seu livro Alegorias do subdesenvolvimento aborda o efeito obtido em Terra em transe com a relação vertical entre imagem e som, que de forma justaposta 
confronta a fala do poeta e seu desejo recalcado. Em passagem bastante esclarecedora sobre ela, diz

\footnotetext{
O som traz a indignação do poeta, sua longa imprecação (...) dirigida contra a (...) vitória de Diaz. As imagens evocam a celebração desta vitória e se desdobram na fantasia invasora de Paulo que a subverte, chegando a empolgar a coroa por um instante enquanto ouvimos sua resposta a Sara na estrada (...) que exalta a sua morte como triunfo de valores absolutos (...) A apresentação simultânea da eloquente fala exterior (Sara) e do fluxo interior (seu desejo) tem, neste ponto, efeito revelador. A montagem vertical som/imagem (...) torna explicito o estatuto de suas últimas palavras como denegação (1993, p.36, grifo nosso)
}

Como o próprio crítico bem ressalta, a denegação não aparece apenas com as últimas cenas do filme, mas atravessa as atitudes do poeta-protagonista e se articula com a sua busca compulsiva de um grande líder assim como por sua fome pelos valores absolutos.

Com a relação vertical entre imagem e som, o filme não apenas discorre sobre as forças objetivas que abalaram o poeta, mas aponta para as forças subjetivas que, não se formam separadas daquelas, e que quando denegadas se tornam progressivamente mais fortes sobrepondo-se a qualquer possibilidade do sujeito escapar de seu círculo mítico.

É aí então que se pode ver um sentido formativo de articular a representação alegórica com a realidade que abala efetivamente a subjetividade, que por sua vez busca se afirmar como não abalada e nessa medida se vê cada vez mais presa a uma espécie de transe.

Esse aspecto é aqui ressaltado para pensar os excessos que caracterizam a estética deste filme e que faz dele algo completamente diferente de filmes que tratam de modo muito marcado e contrastante o lado da subjetividade e/ou da objetividade.

Pensada como algo que transcende a subjetividade do poeta e que adquire sentido em sua experiência concreta, a experiência de transe tematizada no filme, é evocada por suas técnicas. A leitura delas a partir do pensamento de Türcke permite apontá-las como um concentrado de momentos microtraumáticos vivenciados no cotidiano com as imagens audiovisuais. Diante das quais o/a espectador/a revive concentradamente o momento traumático- a desproporção de forças entre o indivíduo, as forças exteriores que o atingemmas também a sua própria fantasia de poder acompanhá-las. Nesse sentido, o filme como uma espécie de overdose em um campo delimitado de encenação abre um espaço para a percepção da estafa diante do próprio fluxo ininterrupto das imagens, e também para aquilo que Türcke (2010b) chama de estresse subcutâneo, advindo da vergonha sentida pelas pessoas 
diante das incomparáveis capacidades de reprodução e registro da tecnologia das imagens.

A estafa é tornada visível seguindo os padrões da experiência subjetiva de repetição e de retardamento. É ela que forma o padrão repetitivo do filme Terra em transe, como se anunciasse a necessidade da subjetividade de re-ver, re-viver, e sobretudo de PAUSAR em meio a extrema turbulência mostrando o transe cada vez mais intenso vivido pela subjetividade que insiste em não re-ver-se, em não re-conhecer seu ritmo e constituição não maquinais como um ser outro, um vir a ser.

De acordo com I. Xavier (2001), Terra em transe combina um tom ritual, de personagens simbólicas que condensam o mundo como verdadeiros emblemas naturais e sociais com uma câmara que se comporta como um documentário. É a câmera que se comporta como tal que consegue apontar que o transe não está fora da realidade mas pode ser visto alegoricamente dentro dela; é ela que consegue evidenciar a condenação de homens e mulheres a repetição de relações de exploração, com suas personificações sociais e naturais que revela a continuidade de uma organização social governada por forças míticas.

Ao radicalizar as mudanças de cenários e planos, a estética de Terra em transe acaba por evidenciar tal continuidade, abrindo espaços de associação não para o que as imagens simplesmente mostram mas para o modo como elas são apresentadas. A saturação de sons, imagens, mudanças rápidas de planos e cenários sempre acompanhada de um enquadramento tremido, desequilibrado, que em alguns momentos atordoa pela dificuldade de acompanhálas, produz o confronto da pretensão do espectador de acompanhá-la com sua própria materialidade sensória ao mesmo tempo que deixa ver a precariedade do registro e da montagem como algo que lhe é também constitutivo. Tal momento de precariedade, geralmente comentado por aqueles que assistem ao filme, também parece ser um elemento chave da força de expressão do filme em relação à precária condição dos sujeitos históricos e sociais diante do assombroso aparato tecnológico.

Em vez de desqualificadas, a brusca mudança de planos e cenas de Terra em transe e seus descompassos diversos frente à imagens alegóricas, provocam uma experiência em direção ao reconhecimento da violência e do transe reproduzidos com a reprodução do contexto violento de desenraizamento progressivo que se torna cada vez mais forte com a desregulamentação neoliberal. Uma violência que consegue ser dissimulada ao passo que deprecia a capacidade demasiadamente humana de produzir imagens mentais, não tão cintilantes e definidas mas incomensuravelmente determinantes para criar/pensar formas de superação das brutais e silenciosas formas de exploração do presente. Uma violência 
conduzida com o deslumbre pelas imagens técnicas e a consequente subordinação constante ao seu fluxo cerrado.

Radicalmente dissimulados no cinema comercial, a mudança de plano e cenários em Terra em transe - o corte- não é índice de sua baixa qualidade mas de sua insistência em reapresentá-lo na própria técnica, como se desconfiasse da capacidade de percepção do/a espectador/a de percebê-lo como tal apenas numa única vez, como se apontasse para resistências do indivíduo de percebê-lo na primeira vez, numa espécie de esforço individual e inconsciente em direção a não percepção do que é ruptura.

Enquanto o cinema comercial de montagem invisível busca eliminar todos os vestígios da presença dos cortes e da edição, a montagem que constitui Terra em transe evidencia-os como um princípio formal que expressa a experiência histórica social e singular. As interrupções que o caracterizam permitem o retomar da condição traumática de isolamento a qual os indivíduos na sociedade capitalista da compra e venda da força de trabalho estão submetidos. Da mesma forma crítica, elas interpelam o sentido da busca isolada e desesperada desses indivíduos armados das mais avançadas tecnologias para reverterem sua situação desesperadora.

São estas interrupções, entretanto, na forma dos cortes, que também expõem a cisão do próprio indivíduo intelectual, que se identifica com o agressor reproduzindo o discurso da força, ao mesmo tempo que acusa o mais fraco socialmente como responsável pela agressão sofrida, pela sua inércia, ou então denuncia o mais forte socialmente como exclusivo responsável pela continuidade da exploração.

\section{Considerações finais}

O filme Terra em transe não apenas pode ser lido como uma alegoria do Golpe de 64 no Brasil, que amplia o espaço de cena em relação aos dois últimos filmes de Glauber Rocha, ou ainda como "alegoria do trópico enquanto palco da empresa colonial e de seus prolongamentos", como bem é apresentado por Xavier, (2001, p. 194) mas também pode, a partir da fundamentação teórica aqui apresentada, ser interpretado como alegoria da exploração da concentração humana em meio a configuração atual do modo de produção capitalista, que, tal como diz Türcke (2010a, 2010b), agudiza o desgaste do sistema nervoso humano. 
É o modo como o filme desenrola uma estética voltada para a retomada do transe, que leva este trabalho a afirmar sua relevância em meio à realidade social cada vez mais reduzida a atualidade, em que o próprio movimento das imagens não permite a atenção das pessoas se deter e assim se ressedimentar. Ou seja, na dificuldade de lidar com os excessos de diferente ordens que caracterizam o filme, emerge a possibilidade do espectador reconhecer o que nele próprio excessivamente se coloca, tal como a sua vergonha de não conseguir efetivamente acompanhar o fluxo das imagens e ainda de não formar imagens de tão excelente resolução como as produzidas pelo arsenal tecnológico.

É para o reconhecimento de um potencial de transformação social nesta impossibilidade de acompanhamento e para a ressignificação do sentimento de vergonha frente as imagens produzidas pelo aparato técnico que Terra em transe é aqui analisado. Assim, com apoio na teoria de Türcke e nas análises de Xavier, o referido filme emerge como uma experiência formativa para professores e professoras reverem o modo como se relacionam com as imagens em movimento e o quê nelas têm valorizado.

\section{Referências Bibliográficas}

BENJAMIN, W. Imagens de pensamento: sobre o haxixe e outras drogas. Tradução de João Barrento. Belo Horizonte: Autêntica editor, 2013.

TÜRCKE, C. Erregte Gesellschft: Philosophie der Sensation. München: Verlag C.H. Beck. 2002

Sociedade Excitada: filosofia da sensação. (Trad. A. Zuin, F. Durão, F. Fontanella \& M. Frungillo). Campinas: Editora da UNICAMP, 2010a.

. Philosophie des Traums. München: Verlag C.H. Beck. 2011.

Filosofia do sonho. Trad. P. R. Schneider. Ijuí: Editora Unijuí, 2010b.

Beck. 2012.

Hyperraktiv! Kritik der Aufmerksamkeitsdefizitkultur. München: Verlag C.H. 2016.

Hiperativos: abaixo a cultura do déficit de atenção. Rio de Janeiro: Paz e Terra,

VIANA, I. Arte política e a tarefa do intelectual em Terra em transe. Baleia na Rede, Marília-SP, Vol.1, n.08, pp. 161-174, 2011. Disponível em <http://www2.marilia.unesp.br/revistas/index.php/baleianarede/article/view/1759>. Acesso 
em: 29 outubro 2017.

XAVIER, Ismail. Cinema brasileiro moderno. São Paulo: Paz e Terra, 2001.

Alegorias do subdesenvolvimento. São Paulo, Brasiliense, 1993.

Sertão-Mar: Glauber Rocha e a estética da fome. São Paulo: Cosac Naify, 2007. 